\title{
Female reproductive health in two lamp factories: effects of exposure to inorganic mercury vapour and stress factors
}

\author{
F DE ROSIS, ${ }^{1}$ S P ANASTASIO,${ }^{2}$ L SELVAGGI, ${ }^{2}$ A BELTRAME, ${ }^{3}$ AND G MORIANI ${ }^{3}$
}

From the Istituto di Scienze dell' Informazione ${ }^{1}$ and $1^{\circ}$ Clinica Ostetrica e Ginecologica, ${ }^{2}$ Università di Bari, Bari, and Ospedale Civile, ${ }^{3}$ Treviso, Italy

\begin{abstract}
To evaluate the possible influence of mercury vapour on female reproduction, 153 women working in a mercury vapour lamp factory have been compared with 193 women employed in another factory of the same company, where mercury was not used. Both groups of subjects were exposed to stress factors (noise, rhythms of production, and shift work). The production process has been analysed by inspection of the plants and by collective discussions with "homogeneous groups" of workers; a retrospective inquiry into work history and reproductive health events has been subsequently performed by an individual interview. Women exposed to mercury vapour currently not exceeding the time weighted average air concentration of 0.01 $\mathrm{mg} / \mathrm{m}^{3}$ declared higher prevalence and incidence rates of menstrual disorders, primary subfecundity, and adverse pregnancy outcome; however, the progression of these problems with the level of exposure to mercury inside the same factory was not always clear. The results of this study neither prove nor exclude the possibility that occupational exposure to this concentration of mercury has a negative effect on female reproduction.
\end{abstract}

The present study was undertaken at the request of the Union of Chemical Workers in order to compare the reproductive health of women working in two factories of the same lamp manufacturing company: mercury vapour used in the production process of one of them was suspected of being responsible for several troubles in the nervous and the reproductive systems that were complained of by the women employed in the factory.

Several experimental and epidemiological studies have shown the harmful effects of mercury vapour on the central nervous system ${ }^{1-3}$; the excess of ovulatory troubles in a group of occupationally exposed women has been interpreted as an indirect consequence of this effect on the pituitary hypothalamic axis. ${ }^{4}$ In addition, placental transfer of inorganic mercury and its vapour has been reported, ${ }^{5}$ and the possibility of a relation between exposure during pregnancy and abortion, perinatal death, growth retardation, and brain damage in the newborn has also been raised. ${ }^{6}$

Most of the results concerning female reproduction have been observed in experimental studies,

Received 23 July 1984

Accepted 17 September 1984 however, and do not allow for a definite assessment of the levels at which there is a risk of adverse health effects for women occupationally exposed during the age of reproduction. A World Health Organisation study group declared, in 1980, that "relatively little is known about the effects of inorganic mercury on the fetus and on reproduction in general. Additional studies on the possible reproduction and fetotoxic effects of inorganic mercury are required."

\section{Subjects and methods}

Since the potential effects of mercury on reproduction are non-specific and may also be produced by other physical or chemical agents, we decided, as the first phase of the inquiry, to make an inventory of the main hazards in the production processes of the two factories. And, since mercury vapours are suspected of affecting not only the outcome of pregnancy, but also other aspects of female reproduction, we extended the subsequent retrospective epidemiological study to some of these aspects such as disturbances of the menstrual cycle and the premenstrual syndrome. As the two factories were 
located in regions far apart (southern and northern Italy), two teams responsible for the inquiry were set up and a common methodology adopted.

\section{PRODUCTION PROCESS AND ITS HAZARDOUS AGENTS}

The production process in the two factories was analysed by an inspection of the plants, and a set of collective discussions with a "homogeneous group" of workers: a homogeneous group is made up of people working together in a line or a shop, thereby having similar or strictly interrelated duties and a high degree of interaction. The results of these collective discussions have been summarised in homogeneous group questionnaires. They included: (a) a detailed description of the production process with its hazardous agents and $(b)$ an evaluation of whether each or all of these agents were compatible with acceptable work practices.

Several stress factors were noted in both factories: noise, rhythms of production, ${ }^{6-14}$ and shift work. ${ }^{14-22}$ In addition, lead alloys were used by some groups for welding lamps and electronic circuits; however, this operation was limited in time and partially automated and therefore did not seem to produce a significant risk of exposure to lead vapour.

The production processes in the two factories were similar: however, mercury was used only in some production lines of the factory located in southern Italy (hereinafter called factory A). It was automatically inserted into each lamp, where vacuum was subsequently produced with a pump: mercury vapours were present around the pumps and the working benches of these lines as a consequence of operational pump defects and broken lamps. Nevertheless, they spread also to other parts of the shop, where all the lines met. According to environmental measurements performed independently and before the start of this study by other research groups, ${ }^{89}$ in the first period after the installation of this factory (1972) the time weighted average mercury air concentration per workshift exceeded, in the most contaminated positions, the then suggested standard of $0.05 \mathrm{mg} / \mathrm{m}^{3}$. A modification of the ventilation system introduced in 1976, however, reduced the concentrations in those positions to average values not exceeding 0.01 $\mathrm{mg} / \mathrm{m}^{3}$ and therefore below the health based limit of $0.025 \mathrm{mg} / \mathrm{m}^{3}$ suggested by WHO in $1980 .^{7}$

From this preliminary study, it seemed that the exposure to mercury vapours in factory $A$ was accompanied by exposure to stress factors, both risk factors being present in the same sections of the production process. This association reduced the possibility of analysing the effect of exposure to mercury on reproductive health, since stress factors are also known to influence the nervous system, and possibly also ovarian function, through the pituitary hypothalamic axis. ${ }^{10}$

Functions performed in factory $A$ were therefore categorised according to the level of exposure to the combination of mercury vapour and stress factors. Two categories were recognised: $(a)$ production lines which used mercury and which involved severe stress factors (higher exposure), and (b) functions where inorganic mercury was not directly used (but where an indirect exposure to the vapour produced by other lines might occur) and which involved mild stress factors (lower exposure). This categorisation of functions allowed us to compare the prevalence of reproductive health problems in two groups of subjects differing in their level of exposure during the period of the interview; it also allowed us to relate the outcome of pregnancy to the level of exposure at the beginning of the pregnancy itself.

The subjects working in the second factory (factory B) were exposed to stress factors of the same average level as factory $A$ but not to mercury vapour nor to other hazardous chemical agents: they were therefore taken as a reference group in order to measure whether a comparatively increased risk for reproductive health existed in factory $A$ from exposure to mercury vapour.

\section{RETROSPECTIVE EPIDEMIOLOGICAL INQUIRY}

At the end of this preliminary phase an individual questionnaire was designed for the female workers in both factories: its purpose was to analyse retrospectively the history of exposure and the main health events after employment in the factory under study. The sections of the questionnaire are given in the appendix. In general, closed questions were used; open questions were introduced only in cases where personal comments by the respondent were essential to understand the problem fully (sexual relations, for example), but the results from these questions will not be analysed in this paper. A few women workers were involved in the phase of questionnaire design and test in both factories in order to increase the clearness and acceptability of questions: this was thought to be important in an inquiry of problems considered "strictly private" by women, where there was a high risk of either refusals or partial and biased replies.

The questionnaire was administered by a female shop steward and by a gynaecologist in a partially standardised interview, although some flexibility was allowed to the interviewers. The worker was requested to recall her work history in a detailed and precise manner with the help of the shop steward: afterwards, the gynaecologist completed the medical 
Table 1 Distribution of selected characteristics of women in the two factories

\begin{tabular}{|c|c|c|}
\hline & Factory $A$ & Factory $B$ \\
\hline $\begin{array}{l}\text { No of women } \\
\text { Age (years): }\end{array}$ & 153 & 293 \\
\hline $\begin{aligned} \leqslant & 20 \\
& 21-30 \\
& 31-40 \\
\geqslant & 41\end{aligned}$ & $\begin{array}{r}3 \% \\
65 \% \\
29 \% \\
3 \%\end{array}$ & $\begin{array}{l}1 \% \\
36 \% \\
46 \% \\
17 \%\end{array}$ \\
\hline Civil status: & & \\
\hline $\begin{array}{l}\text { Unmarried } \\
\text { Married } \\
\text { Other }\end{array}$ & $\begin{array}{r}29 \% \\
64 \% \\
7 \%\end{array}$ & $\begin{array}{r}16 \% \\
77 \% \\
7 \%\end{array}$ \\
\hline $\begin{array}{l}\text { Educational le } \\
\leqslant 5 \\
\quad 6-8 \\
\geqslant 9\end{array}$ & $\begin{array}{l}48 \% \\
38 \% \\
14 \%\end{array}$ & $\begin{array}{r}54 \% \\
40 \% \\
6 \%\end{array}$ \\
\hline $\begin{array}{c}\text { Duration of e } \\
\leqslant 5 \\
6-10 \\
11-17\end{array}$ & $\begin{array}{r}7 \% \\
92 \% \\
1 \%\end{array}$ & $\begin{array}{r}3 \% \\
8 \% \\
89 \%\end{array}$ \\
\hline
\end{tabular}

section of the questionnaire. A common training procedure was established for both interviewing teams.

The interview was administered to 153 of the 193 women employed in factory $A(79 \%)$ and to 293 of the 332 women in factory $B(88 \%)$. Table 1 shows the distribution of women interviewed by age, civil status, educational level, and duration of employment. Most of the women were engaged when the factories were set up (1972 for factory A, 1965 for factory B): this explains the homogeneity of the workers' duration of employment at each factory and the difference between the two factories. This difference, and the difference in the age distribution, was taken into account when the health of the two groups of subjects was compared.

Women interviewed in factory $\mathrm{A}$ had been frequently moved from job to job, each with different levels of exposure. Their work histories have therefore been categorised into two groups according to the level of exposure: those in the first group include those tasks with predominantly higher exposure to mercury vapours and stress factors, whereas those in the second group include tasks with lower exposure on average. This categorisation allowed a comparison to be made in the incidence of health disorders in two groups of subjects differing in their level of average exposure to mercury vapours and stress factors during the period of employment in the factory itself.

\section{Results}

Not all the information collected from the individual interviews has been analysed in the present paper but the most significant results are reported. Some cases have been excluded from the study: the menstrual cycles have been analysed only for women not being in the menopause and who had not taken oral contraceptives during the year preceding the interview. In addition, although complete obstetric histories have been collected (with the exception of induced abortions, which were excluded from the interview), only the pregnancies begun during employment in the factory under study have been taken into consideration: we have not taken previous pregnancies as a reference because of the effect of the many possible confounding factors between working and non-working women, which could not be controlled.

\section{DISORDERS IN THE MENSTRUAL CYCLE}

To evaluate the prevalence of disorders in the menstrual cycle, the cycles have been categorised according to their duration during the year preceding the interview: "normal" cycles ranged from 25 to 31 days, whereas "abnormal" ones corresponded to polymenorrhoea (less than 25 days) or oligomenorrhoea (more than 31 days).

The incidence of these disorders during the period of employment in factory A or B was computed as the number of women having "normal" cycles at their engagement at the factory but who noticed a

Table 2 Prevalence of some reproductive disorders

\begin{tabular}{|c|c|c|c|c|}
\hline & \multicolumn{3}{|l|}{ Factory $A$} & \multirow{3}{*}{$\frac{\text { Factory } B}{\text { Exposure to stress }}$} \\
\hline & \multicolumn{2}{|c|}{ Present exposure to mercury and stress } & \multirow[t]{2}{*}{ Total } & \\
\hline & Higher & Lower & & \\
\hline $\begin{array}{l}\text { No of women interviewed } \\
\text { No of questionnaires examined } \\
\text { Duration of menstrual cycle during past year. }\end{array}$ & $\begin{array}{l}68 \\
60\end{array}$ & $\begin{array}{l}85 \\
76\end{array}$ & $\begin{array}{l}153 \\
136\end{array}$ & $\begin{array}{l}293 \\
241\end{array}$ \\
\hline $\begin{array}{l}\text { Normal } \\
\text { Polymenorrhoea } \\
\text { Oligomenorrhoea } \\
\text { No of married women } \\
\text { Primary subfecundity }\end{array}$ & $\begin{array}{r}37(62 \%) \\
6(10 \%) \\
17(28 \%)\end{array}$ & $\begin{array}{c}52(68 \%) \\
5(7 \%) \\
19(25 \%)\end{array}$ & $\begin{array}{l}89^{*}(65 \%) \\
11(8 \%) \\
36(27 \%) \\
103 \\
10(10 \%)\end{array}$ & $\begin{array}{l}171^{*}(71 \%) \\
21(9 \%) \\
49(20 \%) \\
223 \\
16(7 \%)\end{array}$ \\
\hline
\end{tabular}


Table 3 Incidence rate of disorders in the menstrual cycle during the exposure period (38 women of factory A have not been included in this table because their exposure could not be clearly categorised)

\begin{tabular}{|c|c|c|c|c|}
\hline & \multicolumn{3}{|l|}{ Factory $A$} & \multirow{3}{*}{$\frac{\text { Factory } B}{\text { Exposure to stress }}$} \\
\hline & \multicolumn{2}{|c|}{$\begin{array}{l}\text { Average exposure to mercury and } \\
\text { stress during working life }\end{array}$} & \multirow[t]{2}{*}{ Total } & \\
\hline & Higher & Lower & & \\
\hline \multirow{4}{*}{$\begin{array}{l}\text { No of questionnaires examined } \\
\text { No of women who noticed an exacerbation } \\
\text { of the premenstrual syndrome } \\
\text { No of women having normal cycles at start of } \\
\text { employment } \\
\text { No of women who noticed a change in the } \\
\text { menstrual cycle }\end{array}$} & 86 & 20 & 106 & 241 \\
\hline & $33(38 \%)$ & $5(25 \%)$ & $38(36 \%)$ & $44(18 \%)$ \\
\hline & 75 & 14 & 89 & 195 \\
\hline & $35(47 \%)$ & $3(21 \%)$ & $38(43 \%)$ & $46(24 \%)$ \\
\hline
\end{tabular}

subsequent change in one of the parameters that usually characterise the cycle (length, duration, and amount of blood loss); a decrease of variability in the cycle length has been excluded from the computation, being commonly considered as "physiological" in the age range 20 to 40 years. " Exacerbation of the premenstrual syndrome was considered as a possible pathological finding, since troubles in the nervous system and in hormonal equilibrium are thought to affect primary dismenorrhoea and other premenstrual symptoms. ${ }^{12}$

The prevalence and incidence rates of disorders in the menstrual cycle were higher in factory A (tables 2 and 3), with a tendency towards oligomenorrhoea: the age standardised rate ratio of abnormal cycles, taking factory $\mathrm{B}$ as a reference, was $1 \cdot 4 .^{13}$ The difference in incidence rates is important if one considers that the period of observation in factory $B$ was much longer than the corresponding period in factory A (15 compared with eight years on average: see table 1).

A relation between the prevalence and incidence of menstrual disorders and levels of exposure in factory A may also be noted in tables 2 and 3: as mentioned in the previous paragraph, the exposure in the period of interview has been used for comparing prevalence rates, whereas the average exposure during the entire working life in the factory has been related to the incidence rates.

\section{PRIMARY SUBFECUNDITY}

The prevalence of this condition (defined as "failure to achieve a first pregnancy after engaging in sexual activity without contraception, for a period of one year or longer") ${ }^{14}$ was higher in the married couples at factory $\mathbf{A}$.

\section{ADVERSE PREGNANCY OUTCOMES}

Since maternal age at pregnancy was distributed unequally in the two factories (table 4), the corresponding rates have been age standardised; since the rates of smoking and alcohol consumption during pregnancy were generally low, standardisation for these factors was not necessary.

Table 4 Outcomes of pregnancies begun during employment in factories under study

\begin{tabular}{|c|c|c|c|c|}
\hline & \multicolumn{3}{|l|}{ Factory $A$} & \multirow{3}{*}{$\begin{array}{l}\text { Factory } B \\
\begin{array}{l}\text { Exposure to stress } \\
\text { during pregnancy }\end{array}\end{array}$} \\
\hline & \multicolumn{2}{|c|}{$\begin{array}{l}\text { Exposure to mercury and stress } \\
\text { during pregnancy }\end{array}$} & \multirow[t]{2}{*}{ Total } & \\
\hline & Higher & Lower & & \\
\hline \multirow{7}{*}{$\begin{array}{l}\text { No of pregnancies } \\
\text { Maternal age at pregnancy (year): } \\
\quad \leqslant 20 \\
\quad 21-29 \\
30-34 \\
\geqslant 35 \\
\text { Rate of spontaneous abortion } \\
\text { Overall pathology of pregnancy } \\
\text { No of births } \\
\text { Low birthweight ( } \leqslant 2500 \mathrm{~g} \text { ) } \\
\text { Malformation rate } \\
\text { Perinatal deaths (until } 28 \text { days after birth) } \\
\text { Postneonatal deaths (from } 28 \text { days to } 1 \text { year) }\end{array}$} & 52 & 68 & 120 & 254 \\
\hline & & & $\begin{array}{c}10(8 \%) \\
101(84 \%) \\
7(6 \%) \\
2(2 \%)\end{array}$ & $\begin{array}{c}23(9 \%) \\
178(70 \%) \\
35(14 \%) \\
18(7 \%)\end{array}$ \\
\hline & $\begin{array}{r}6(12 \%) \\
17(33 \%)\end{array}$ & $\begin{array}{r}8(12 \%) \\
28(41 \%)\end{array}$ & $\begin{array}{l}14(12 \%)^{*} \\
45(37 \%) \dagger\end{array}$ & $36(14 \%)^{*}$ \\
\hline & & 60 & 106 & 218 \\
\hline & & & $\begin{array}{l}3(3 \%) \\
7(7 \%)\end{array}$ & $\begin{array}{l}6(3 \%) \\
7(3 \%)\end{array}$ \\
\hline & & & $2(10)$ & 2 \\
\hline & & & 1 & 2 \\
\hline
\end{tabular}

Age standardised rate ratios: (taking factory B as a reference).

*SRR Sp abortions $=1$.

tSRR ov path of pregnancy $=1 \cdot 2$. 
After age correction, the rates of spontaneous abortions in factories A and B are similar, but a slight difference remains in the rates of "overall pathology of pregnancy," a sategory including pregnancies where any of the following events have occurred: threatened abortion (vaginal bleeding in early pregnancy), spontaneous abortion, threat of premature delivery, or preterm delivery (before 37 weeks of gestation). By contrast, the malformation rate was much higher in factory $A$ : however, six of the seven cases in this factory were congenital dislocations of the hip (no such case occurred in factory B) and the difference between the two factories could be due to a different prevalence of this condition in northern and southern Italy.

The comparison of the two groups of pregnancies in factory $\mathrm{A}$ does not show a clear relation between adverse outcomes of pregnancy and level of exposure during pregnancy: the rates of spontaneous abortions are equal, whereas the pregnancies with lower exposure seem to have had a higher rate of "overall pathology," which is partially due to a repetition of pregnancies with "negative events" (see the above definition) during their course, in the same woman.

\section{Discussion}

Reference values for the frequency of reproductive health disorders in the general population in Italy are not available: the results of this study may therefore be evaluated only with reference to other published studies. On this basis it may be seen that the subjects working in factory $\mathrm{A}$, where mercury was used, had, during their 1043 man-years of exposure, none of the serious pathological effects that occurred during epidemics of poisoning with organic mercury compounds in Minnamata, Iraq, and the USSR. ${ }^{6}$ The abortion rate was only slightly higher than the average value (10\%) found in an inquiry on about 4000 women working in the textile, chemical, and mechanical industries in Italy (I Figa Talamanca, at Rome Seminar, 1984), which used an identical questionnaire. This rate is also comparable with the values found in studies based on hospital registers in some Scandinavian countries, ${ }^{1516}$ (B Kolmodin-Heldman, L Hedström, International Course on Occupational Hazards and Reproduction, Helsinki, 1981), although the method of data collection seems to give a different estimation of spontaneous abortions (ML Niemi, K Hemminki, Helsinki, 1981). The perinatal and postneonatal death rates were not high nor was the frequency of low birth weight. No case of malformation could be specifically ascribed to mercury.

Unfortunately, data on spontaneous abortions could not be validated from hospital records; in Italy the Abortion Act of 1976 did not succeed in eradicating illegal abortions and therefore a proportion of women admitted to hospitals for "spontaneous" abortion have already had an unsuccessful induced abortion, and this proportion cannot be evaluated.

So far as an internal comparison between the two factories is concerned, the women exposed to mercury declared a higher prevalence and incidence of disorders in their menstrual cycles than those not exposed: this increased risk seems to be directly related to the level of exposure to mercury and stress. The tendency towards oligomenorrhoea agrees with the results of the study by Panova, who showed an excess of ovulatory troubles in 60 women working in a lamp factory as judged from vaginal smears. ${ }^{4}$ This tendency could be explained by the combined effect of mercury vapour and stress factors on the pituitary hypothalamic axis; exposure to stress may explain why the women exposed only to stress factors in factory $B$ have a lower prevalence of "normal" cycles than the values $(80 \%)$ found in a prospective inquiry on 2000 non-exposed volunteers $^{11}$ in the same age group. The exacerbation of the premenstrual syndrome could not be regarded as "physiological", considering that these complaints seem to recede with childbearing and age,${ }^{17}$ and may also be ascribed to troubles in hormonal equilibrium.

The adverse pregnancy outcomes are, however, not clearly related to exposure to mercury. To examine this inconsistent finding, we have compared the courses of pregnancies in the two factories. A higher proportion of the cases of threatened abortion in factory $A$ had obtained maternity leave than in factory $\mathrm{B}$, and a lower proportion of these cases had ended in a spontaneous abortion in the same factory. Without asserting that a causal relation exists between these two findings, it may be noted that precautionary measures have been taken in factory A (probably due also to the awareness that $\stackrel{9}{\supset}$ there was a risk from mercury) which might have $\frac{D}{\square}$ contributed partially to protect the outcome of pregnancies. In addition, the true abortion rate in N factory A may have been underestimated if some of the long menstrual cycles declared (45 to 60 days) $N$ were actually early abortions. This suspicion rein- $\mathrm{W}$ forced us. in the conviction that, in epidemiological inquiries, the analysis of pregnancy outcomes should $o$ be integrated with the analysis of other relevant $\stackrel{\mathscr{D}}{\mathscr{N}}$ aspects of reproduction, and of menstrual cycles in ? particular.

Our results, therefore, do not allow us either to prove or to exclude the possibility that occupational $\stackrel{\unrhd}{\Omega}$ exposure to mercury vapour concentrations not $\mathbb{\mathbb { Q }}$ 
exceeding the TWA value of $0.05 \mathrm{mg} / \mathrm{m}^{3}$ has a greater negative effect on the female reproductive system than the workload and the stress of other industrial tasks. This conclusion does not permit us to disregard the risk of exposure to mercury in the factory examined: the WHO recommendation that "the exposure to mercury vapour of women in childbearing age should be as low as possible" ${ }^{3}$ should be observed by adopting more effective safety measures and introducing periodical controls.

Some final consideration should also be given to methodological aspects. This study was based on the assumption that direct and active cooperation of the workers in an epidemiological inquiry is an essential condition for at least two objectives: to promote the use of the results in support of an immediate preventive action and to obtain a high response rate and thus more accurate information, particularly in matters considered "strictly private" (questions concerning female reproductive health certainly fall into this category).

In our experience the collective discussions with homogeneous groups of workers in the first phase of the inquiry helped to achieve cooperation in this and subsequent phases of the study. In addition, this combination of discussion with homogeneous groups (preceded by an inspection of the plants) and subsequent individual interviews allowed us to avoid the possible recall bias in the retrospective assessment of exposure (different levels of recall in women having had negative or positive outcomes of their pregnancies, or being in different health). In the individual interview only a list of jobs performed was collected: this referral seems to be quite reliable and independent of the health status ( $O$ Axelson, Helsinki 1981); the matrix of jobs risk factors defined as a result of the first phase was subsequently linked to the work history to define the levels of exposure in the period of interview at the beginning of the pregnancy or during the whole of the subjects' working life.

Nevertheless, when adopting this approach one should take into account the methodological and operational difficulties entailed. In particular, the study is not "blind", since interviewers and responders are aware of its objectives and the results of each phase; in addition, the workers know in advance that they may be able to use the results to require changes in their working conditions. It is likely, therefore, that the prevailing industrial and economic conditions will have an effect on the workers' response. These conditions might influence the collective estimation of the hazard, as well as the individual assessment of health.

Whether this new risk of error is counterbalanced by the advantages we have tried to emphasise, is open to discussion.

We thank Professor $O$ Axelson, University of Linkôping, for his helpful suggestions and criticisms.

\section{Appendix}

\section{INDIVIDUAL QUESTIONNAIRE SECTIONS \\ 1 General information}

Age, years of education, civil status, smoke (number of cigarettes a day and number of years of smoking), drugs taken more that once a month, travelling to the workplace.

\section{Work history}

A list of jobs before engagement in the present factory and a detailed sequential list of all the functions performed in this factory, with the duration for each.

\section{Workload of domestic activities}

Numbers of children under 15 years old and of those aged over 65 living with the family; amount of domestic help received.

\section{General health status}

An open question to report a list of past diseases and present troubles.

\section{Reproductive health}

Contraceptive methods.

Characteristics of menstrual cycle during past year (minimum and maximum cycle duration, duration and amount of blood loss); variations of these characteristics since menarche (type of variations and approximate year of onset).

Premenstrual syndrome, defined as "a combination of emotional and physical features which occur cyclically in a female before menstruation, and which regress or disappear during menstruation. ${ }^{15}$ The following symptoms have been considered: dysmenorrhea, breast tension, irritability, backache, nausea, depression, difficulty in concentrating, and swelling of the hands and the ankles.

Gynaecological troubles.

Subfecundity, its duration and eventually known causes.

Problems in sexual relation.

Obstetric history. For each pregnancy: homogeneous group during pregnancy, beginning of maternity leave, course (obstetrical controls, maternal increase of weight, main diseases, threats of abortion and of premature delivery), course of delivery and its issue (including duration of pregnancy in weeks and weight of baby), health of baby during first year of life (malformations, diseases, and distresses). 
494

\section{References}

' Richter ED, Peled N, Luria M. Mercury exposure and effects at a thermometer factory. Scand J Work Environ Health 1982;8:161-6.

${ }^{2}$ Vroom F, Greer M. Mercury vapour intoxication. Brain 1972;95:305-18.

${ }^{3}$ World Health Organisation. Recommended health-based limits in occupational exposure to heavy metals. Geneva: WHO, 1980. (TRS 647.)

4 Panova Z, Dimitrov G. Changes in ovarian function and some functional liver indices in occupational contact with metallic mercury. Akush Ginecol (Mosk) 1976;15:133-7.

${ }^{5}$ Clarkson TW, Greenwood MR, Magos L. The transport of elemental mercury into fetal tissues. Biol Neonate 1972;21:239 44.

- Koos BJ, Longo LD. Mercury toxicity in the pregnant mother, fetus and newborn infant. Am J Obstet Gynecol 1976;126:390-409.

1 World Health Organisation. Environmental health criteria for mercury. Ambio 1978; 7:28-30.

B Istituto di Medicina del Lavoro Università di Bari. Relazione igienicoambientale sulla OSRAM. Bari: 1976. (Internal report.)

${ }^{9}$ Istituto di Medicina del Lavoro Università di Pavia. Relazione de Rosis, Anastasio, Selvaggi, Beltrame, and Moriani sull'indagine clinico-strumentale alla OSRAM SUD. Pavia: 1980. (Internal report.)

${ }^{10}$ Peyser MR, Ayalon D, Harell A, Toaff R, Cordova T. Stress induced delay of ovulation. Obstet Gyn 1973;42:667-71.

" Chiazze L, Brayer FT, Macisco JJ, Parker MP, Duffy BJ. The length and variability of the human menstrual cycle. JAMA 1968;203:89-92.

12 Anonymous. Premenstrual syndrome [Editorial]. Lancet 1981;ii: $1393-4$.

${ }^{13}$ Axelson O. Methodological aspects in occupational health epidemiology on reproductive hazards. Seminario di Aggiornamento su 'attivita lavorativa e salute riproduttiva della donna' Bari. Bologna: Monduzzi, 1983.

14 Rachootin PM, Olsen J. Prevalence and socioeconomic correlates of subfecundity and spontaneous abortion in Denmark. Int J Epidemiol 1982;11:245-9.

is Hansson E, Jansa S, Wande H, Källen B, Ostlund E. Pregnancy outcome for women working in laboratories in some of the pharmaceutical industries in Sweden. Scand $J$ Work Environ Health 1980; 6:131-4.

${ }^{10}$ Hemminki K, Franssila E, Vainio H. Spontaneous abortions among female chemical workers in Finland. Int Arch Occup Environ Health 1980;45:123-6.

17 Bergsjo P, Jenssen H, Vellar OD. Dysmenorrhea in industrial workers. Acta Obstet Gynecol Scand 1975;54:255-9. 